\title{
O USO INTENSIVO DAS REDES SOCIAIS E A REESTRUTURAÇÃO NO AMBIENTE DE TRABALHO DE EMPRESAS DE UMA CIDADE MÉDIA DA BAHIA
}

\author{
The intensive use of social networks and the restructuring in the working environment \\ of companies in a middle-sized city in Bahia
}

\section{El uso intensivo de las redes sociales y La reestructuración em el ambiente de trabajo de empresas de una ciudad media de Bahia}

\author{
Lumena Carvalho Andrade ${ }^{1}$ \\ Lúcio dos Santos Carvalho ${ }^{2}$ \\ Marcelle Bittencourt Xavier Almeida ${ }^{3}$
}

${ }^{1}$ Graduada em Administração pela Faculdade Independente do Nordeste (FAINOR), e-mail: inh4_vca@hotmail.com

${ }^{2}$ Professor da Universidade Estadual do Sudoeste da Bahia (UESB),membro do Colegiado de Medicina, e-mail: lucioscarvalho@ hotmail.com ${ }^{3}$ Mestranda em Letras: Cultura, Educação e Linguagens (PPGCEL) na Universidade Estadual do Sudoeste da Bahia (UESB), e-mail: bittencourt.marcelle@gmail.com

\begin{abstract}
Resumo
Esta pesquisa objetivou averiguar a reestruturação no ambiente de trabalho de empresas de uma cidade média, a partir do uso mais intensivo das redes sociais. Em termos metodológicos, para o artigo em questão utilizou-se de pesquisas de natureza exploratória e descritiva, com abordagem quantitativa. A estratégia para coleta de dados foi baseada em pesquisa de campo, com a participação de empresas de segmento de venda de confecção, em Vitória da Conquista, segunda mais importante cidade média do Estado da Bahia. Constatou-se que $86,67 \%$ dos casos são os próprios funcionários que ficam incumbidos para implantar a gestão das redes sociais, ficando evidenciado um processo de adaptação dos funcionários à realidade imposta pelos novos recursos tecnológicos no âmbito das redes sociais.
\end{abstract}

Palavras-chave: Cidade média; Reestruturação produtiva; Redes sociais.

\begin{abstract}
This research aimed to investigate the restructuring in the work environment of companies in a medium city, from the more intensive use of social networks. In methodological terms, for the article in question we used exploratory and descriptive research, with a quantitative approach. The strategy for data collection was on field research, with the participation of companies in the apparel segment, in Vitória da Conquista, the second most important city in the state of Bahia. It was verified that $86,67 \%$ of the cases are the employees themselves who are entrusted with the implementation of the management of social networks, showing a process of adaptation of the employees to the reality imposed by the new technological resources in the scope of social networks.
\end{abstract}

Keywords: Average city; Productive restructuring; Social networks. 


\section{Resumen}

Esta investigación objetivó averiguar La reestructuraciónenel ambiente de trabajo de empresas de una ciudad media, a partir del uso más intensivo de las redes sociales. En términos metodológicos, para el artículo encuestión se utilizó de investigaciones de naturaleza exploratoria y descriptiva, com abordaje cuantitativo. La estrategia para La recolección de datos se basó em La investigación de campo, com La participación de empresas de segmento de venta de confección, en Vitória da Conquista, la segunda ciudad más importante del Estado de Bahia. Se constató que el 86,67\% de los casos son los propios funcionarios que se encargan de implantar lagestión de las redes sociales, quedando evidenciado um proceso de adaptación de los funcionarios a La realidad impuesta por los nuevos recursos tecnológicos em el ámbito de las redes sociales.

Palabras clave: Ciudad media; Reestructuración productiva; Redes sociales.

\section{Introdução}

No final da década de 1990, já era perceptível o surgimento de novas tecnologias na área da informática e equipamentos associados, a exemplo de aparelhos celulares, webcams e as TVs interativas (CASTELLS, 2000). Assim, as novas tecnologias possibilitaram a convergência entre as mídias e a internet, bem como a linguagem digital gerou mudanças na infraestrutura de transmissão de dados, sons e imagens.

Esse contexto de transformações no início do século XXI despertou uma forte expectativa em relação às novas possibilidades de mudanças nas cadeias produtivas e na sua reestruturação organizacional (FONSECA, 2005). Geralmente, em um ambiente empresarial rodeado por concorrências cada vez mais acirradas, muitas organizações buscam utilizar tecnologias que lhes proporcionem adequação às novas arquiteturas de redes produtivas, notadamente, nos processos de comunicação interna e externa.

Atualmente, as redes sociais compõem um tipo de tecnologia que podem empresas a aprimorar o processo de comunicação interna e externa. Elas são ambientes virtuais que permitem que as pessoas estabeleçam constantes trocas de informações e quando devidamente criadas, controladas e executadas, podem gerar excelentes resultados a curto, médio e longo prazo, como destaca Luiz Otávio Mariano, Diretor de Marketing Digital (MARIANO, 2017, p. 1).

Diante disso, o presente artigo apresenta os principais resultados de uma investigação que objetivou averiguar a reestruturação no ambiente de trabalho em empresas de uma cidade média, a partir do uso mais intensivo das redes sociais. Buscou-se conhecer como as redes sociais são usadas no segmento de confecções da cidade de Vitória da Conquista, Bahia. Além disso, foram almejadas respostas para as seguintes questões: Como as empresas do 
citado segmento tem feito uso de redes sociais? Qual a infraestrutura que essas empresas disponibilizaram para as atividades de gestão das redes sociais? Em qual frequência elas fazem uso das redes sociais? Quais as principais redes sociais utilizadas?

Ressalta-se que em uma investigação mais ampla foram utilizados dados qualitativos e quantitativos. Todavia, nesta seção deste trabalho serão descritos apenas os procedimentos metodológicos com abordagem quantitativa que contribuíram para compreender como as lojas de confecção de Vitória da Conquista fazem uso das redes sociais. Assim, no estudo mais amplo, não descrito neste trabalho, utilizou-se, numa primeira etapa de uma pesquisa exploratória sobre o objeto de estudo, o que possibilitou a geração de elementos necessários para definiçãa das questões de pesquisa e do objetivo da investigação. Em uma segunda etapa, nova pesquisa de natureza exploratória e uma pesquisa de campo foram base para o processo de coleta e análise de dados, bem como elaboração da conclusão do estudo.

Assim, em uma fase que antecedeu esta etapa descritiva, foram realizadas observações in loco, conversas informais com gestores e funcionários de lojas de confecções do segmento escolhido para estudo, além de leituras de fontes bibliográficas que tratam da reestruturação produtiva e organizacional e uso de redes sociais no âmbito empresarial.

A partir das informações preliminares, percebeu-se que era pertinente escolher o método de estudo de caso para obter respostas confiáveis para a análise do problema de pesquisa. Em conformidade com Yin (2001), o estudo de caso é recomendável para análise de uma situação que exige uma inquirição empírica de um fenômeno contemporâneo dentro de um contexto da vida real no qual não é claramente evidente a delimitação do contexto e o fenômeno e quando é preciso utilizar de múltiplas fontes de evidência para se chegar à conclusão do estudo.

$\mathrm{Na}$ etapa de natureza quantitativa, foi usada uma amostragem não probabilística, intencional. Participaram das entrevistas os gestores de 15 (quinze) empresas.

Ao coletar as informações, os trâmites burocráticos para observância dos aspetos éticos foram considerados, sendo preparado um formulário contendo um conjunto de variáveis previamente escolhidas para analisar o uso das redes sociais. Após a coleta, procedeu-se tabulação dos dados no software SPSS IBM, versão 20. Em seguida, realizou-se a descrição e a análise dos dados, correlacionando os achados com o aporte teórico selecionado.

\section{Reestruturação produtiva}


Os processos de mudanças no mundo contemporâneo são marcados pelas tensões entre o novo e o velho. Nas últimas décadas, ocorreram muitas mudanças que têm gerado impactos na organização da sociedade contemporânea (HOBSBAWN, 2008). Ocorreram, por exemplo, a intensificação da globalização, a reestruturação produtiva do capital e redesenho de modelos de gestão das empresas. É inegável que os avanços tecnológicos têm expandido o alcance à internet e às redes sociais, mudando o conceito das empresas e afetando o comportamento dos consumidores.

Thompson (1999) afirmou que a globalização no seu sentido mais amplo deu origem às formas complexas de interação e interdependência. Trata-se, de um processo que abrange mais do que a expansão das atividades para além das fronteiras de estados nacionais. $\mathrm{Na}$ globalização, as atividades ocorrem em uma arena global que tem impacto sobre atividades locais, gerando uma nova arquitetura difusa de interconexões de diferentes lugares e pessoas.

No atual contexto de expansão das tecnologias da informação, o modelo tayloristafordista ainda continua sofrendo mudanças em razão da incorporação de alta tecnologia na produção (CASTELLS, 2000), a exemplo da microeletrônica, inteligência artificial, redes neurais e da robótica.

Parafraseando uma expressão utilizada por Guatarri (1986), é pertinente dizer que as novas arquiteturas de organização das empresas levam a geração de "subjetividade do capitalismo", essa no atual contexto, cada vez mais integrada à globalização, uma vez que a aldeia global favorecer a criação de identidades interligadas pela liberdade de consumo (GUIMARÃES, 2007), ou seja, liberdade no comportamento do consumo. Com o comércio eletrônico e as redes sociais o modo de interação das empresas com os consumidores sofreu significativas mudanças.

Assim, os recursos tecnológicos computacionais estão alterando radicalmente as formas de trabalho, pois as empresas estão cada vez mais buscando conhecimento científico e alta tecnologia para obter vantagem em relação à concorrência. Nessa perspectiva de reestruturação nas organizações, Oliveira (2003) argumentou que os novos arranjos produtivos requerem a convivência harmônica entre o arcaico e o moderno, entre empresas que fazem uso de recursos tecnológicos e aquelas que ainda não se atentaram para a importância desses recursos.

$\mathrm{Na}$ aldeia global que tem possibilitado um crescimento cada vez maior da internet e das redes sociais, na avaliação de Haesbaert (2004), essas redes contemporâneas são um tipo de território possuidor de significativa carga imaterial e, por conseguinte, devem ser estudadas “[...] enquanto componentes dos processos de territorialização (e não simplesmente de desterritorialização) [...], pois “[...] configuram territórios descontínuos, fragmentados, 
superpostos, bastante distintos da territorialização dominante na chamada modernidade clássica.” (p. 281)

Assim, ao argumentar sobre novos arranjos na organização do território, Haesbaert (2004) enfatiza que, em relação à expansão das redes contemporâneas, há um processo de reterritorialização, ao invés de desterritorialidade. Enfatizou que há uma reterritorialização de relações sociais construídas por intermédio de territórios-rede, sobrepostos e descontínuos, ao invés de territórios-zona. Esses estão na aldeia global, na modernidade clássica territorialestatal, no âmbito do denominado capitalismo de acumulação flexível. As formas tradicionais de territórios passaram a formar "[...] um amálgama complexo com as novas modalidades de organização territorial”. (HAESBAERT, 2004, p. 338).

Por conseguinte, a reestruturação produtiva não é resultado apenas da ideia de que o capital busca exercer maior controle social sobre o trabalho. Os novos arranjos das redes de computadores e das redes sociais têm gerado ampliação das capacidades humanas, mediante avanços tecnológicos e informacionais que têm eliminado tradicionais postos de trabalho e gerado novos (ALVES, 2000), além de intensificar a produtividade. Para Antunes (1999), o sistema capitalista tem influência direta no comportamento de compra dos consumidores.

\section{As mídias sociais e as redes sociais}

O uso das redes sociais como forma de comunicação tem tomado proporções cada vez maiores no mundo atualmente (RECUERO, 2009). De acordo com pesquisas publicadas na Magoweb (2014), o Brasil é o $4^{\circ}$ país do mundo com mais acesso às redes sociais; $97 \%$ dos internautas brasileiros estão em alguma rede social; $79 \%$ das compras na América Latina são influenciadas por recomendações em Redes Sociais.

Pesquisa publicada por Owyang (2009 apud SANTIAGO, 2009), feita com empresários que utilizam as mídias sociais em 24 empresas, também revela o desenvolvimento das redes sociais em cinco eras, que ainda denominamos de ondas: a onda de relações sociais, na qual as pessoas são conectadas com outras pessoas para compartilhar; a onda da funcionalidade social, cujas redes sociais tornam-se sistemas operacionais; a onda da colonização social, em que toda experiência pode ser social; a onda do contexto social, que exige um conteúdo pontual e personalizado; e a onda do comércio social, cujas comunidades definem futuros produtos e serviços.

Essas ondas não são sequenciais; mas sim sobrepostas, ou seja, em cada fase da evolução foram acrescentadas características que comprova o quanto se faz necessário o uso 
das redes sociais como forma de comunicação, principalmente entre as organizações e os indivíduos.

O que se acredita é que os consumidores irão cada vez mais confiar em seus pares e tomar decisões online independentemente da participação das marcas. Isto permitirá que as pessoas tomem decisões de consumo sem a influência das marcas ou de sistemas de CRM (CustomerRelationship Management). As marcas vão seguir os consumidores que por sua vez definirão os novos produtos (OWYANG, 2009 apud SANTIAGO, 2009, p. 49).

Com a evolução das redes sociais fica claro que as mesmas deixaram de ser apenas meios de comunicação e passaram a ser uma ferramenta formadora de opinião. A onda do comércio social é uma realidade presente na sociedade e serve de alerta para as empresas que ainda não se adaptaram as redes sociais.

As redes sociais trouxeram grandes avanços para as organizações em termos de relacionamento com os clientes (FUSCO, 2009 apud CIRIBELI; PAIVA, 2011), sendo que elas são responsáveis por gerar relações voluntárias, liberdade de expressão e espontaneidade que auxiliam na escolha de um produto ou um serviço (CIRIBELI; PAIVA, 2011).

\section{Tipos de redes sociais}

Existem diversas formas de redes sociais que são adaptáveis de acordo com perfil e objetivo de cada indivíduo. Segundo Santos (2014), com o crescimento das redes sociais e a inovação dos aplicativos, é necessário estar sempre alerta ao impacto gerado pelos públicos virtuais e suas audiências consideráveis para a realização de novos investimentos.

A seguir, serão apresentadas informações sobre os três principais tipos de redes sociais utilizados no Brasil.

\section{Twitter}

Quintanilha (2012) ao conceituar o Twitter afirmou que esse tipo de rede social é uma ferramenta que possibilita a troca de mensagens rápidas entre os usuários. Segundo Spyer et al., 2007, p. 8) é o mundo real se misturando cada vez mais com o virtual.

A velocidade de propagação das informações nessa mídia é bem alta e, por isso, existem inúmeras possibilidades e oportunidades a serem exploradas pelas empresas e pessoas.

O funcionamento do Twitter se dá através de um serviço que permite enviar e ler mensagens, conhecidas como tweets(posts de mensagens de texto com até 140 caracters que são mostradas na página do perfil do autor). Os tweets são entregues a todos os seus 
seguidores, conhecidos como followers. Eles podem ser enviados pela web (site do Twitter ou vários outros clientes) ou celular (SMS ou web). Os perfis dos usuários podem ser abertos permitindo acesso de qualquer pessoa, ou fechados, de modo que apenas os followers recebam os tweets (QUINTANILHA, 2012).

Segundo pesquisas realizadas pelo site Magoweb (2014), mais de metade dos usuários ativos no Twitter seguem empresas, marcas ou produtos em redes sociais, além disso, 79\% dos usuários do Twitter estão propensos a recomendar as marcas que eles seguem.

\section{Facebook}

De acordo com Santos (2014), mais de 80\% das empresas usam o Facebook. A rede possui em torno de dois bilhões de usuários registrados em todo o mundo, sendo que "[...] um usuário gasta em média 405 minutos no Facebook todos os meses, o que equivale a 13 minutos por dia" (QUINTANILHA, 2012, p. 29). Geralmente, as empresas fazem uso do Facebook para identificar o perfil do seu público-alvo, conhecer suas preferências e estabelecer um relacionamento constante e estável com o consumidor (PORTO, 2014).

Os participantes do Facebook podem trabalhar com perfis ou Fan Page. O Perfil é feito para pessoas; não faz anúncios nem monitora o desempenho, tendo capacidade adicionar até 5000 amigos. Por sua vez, a Fan Page é mais aconselhada para as empresas, pois possibilita anúncios e monitoramento de desempenho, além de proporcionar uma capacidade de amigos maior, possibilitando a conexão com milhões de pessoas.

Pesquisa realizada na Magoweb (2014) revelaram que mais de 70\% dos usuários adultos de Internet no Brasil estão no Facebook, sendo que 1 em cada 8 minutos gastos na internet é destinado à essa rede social.

\section{Instagram}

O Instagram em pouco tempo se tornou a rede social $100 \%$ móvel mais utilizada da atualidade. Significou uma grande revolução nas imagens, pois possibilita que as pessoas tirem fotos e apliquem filtros simples, causando efeitos de aparência profissional em poucos segundos. Além disso, torna possível o compartilhamento com os amigos e permite a integração com outras redes sociais, como o Facebook.

A instantaneidade proporcionada por essa rede social e a necessidade de exposição cada vez maior das pessoas, faz do Instagram um ótimo instrumento de marketing para as empresas. Para Piza (2012), o Instagram é uma rede social que tem como lógica a intenção de "ver e ser visto", ou seja, quando se publica um conteúdo, automaticamente este poderá ser visualizado por qualquer pessoa que tenha permissão na rede ou que esteja envolvido nela.

As empresas podem utilizar os recursos do Instagram e sua facilidade de interação para divulgarem suas marcas através de fotos dos produtos ou que 
tenham a ver com seu nicho de mercado. Com um perfil semelhante ao do Twitter, podem seguir perfis interessantes e serem seguidos por seus consumidores. (QUINTANILHA, 2012, p.43).

O Instagram é uma rede social que caiu no gosto dos brasileiros, principalmente depois que o Facebook comprou essa empresa e estabeleceu uma parceria de sucesso.

\section{Uso estratégico das redes sociais nos negócios}

De acordo com dados do site Deloitte (2010 apud PEREIRA, 2011), as empresas fazem uso das redes sociais buscando: aumentar a reputação da marca (85\%); inovar o modelo de negócios (53\%); criar vantagem competitiva (59\%); (50\%) trazer ideias de fora da empresa (50\%); gerar mais marketing boca-a-boca (82\%); melhorar o relacionamento com parceiros de negócio (43\%); aumentar a fidelidade do cliente $(57 \%)$; $(41 \%)$ potencializar o sucesso de novos produtos (41\%); aumentar as vendas (55\%); e melhorar a qualidade do suporte ao cliente $(38 \%)$.

Com essa diversidade de objetivos, cabe destacar que cada vez mais surgem estratégias para: consolidação das marcas (VILHA; AUGUSTINI, 2002 apud SANTIAGO, 2009); criar boa imagem da marca (FURLAN; MARINHO, 2014); divulgação de produtos (TORRES, 2010); análise de concorrentes (JOHANN, 2011; PORTO, 2014); identificar perfis (ECMETRICS, 2011; FERREIRA, 2013); prestação de serviços de pré-venda e pós-venda (BANA, 2013; FURLAN; MARINHO, 2014).

Em relação aos dados específicos das empresas de confecção, identificou-se que 93,33\% delas são de micro ou pequeno porte, possuindo até cinco funcionários. Das empresas pesquisadas, $80 \%$ têm entre um e seis anos de atuação no mercado, sendo que dessas, $60 \%$ atuam no mercado entre 1 a 3 anos, e $20 \%$ de 4 a 6 anos.

Com base nos dados constados do Quadro 1, é válido afirmar que entre as sete modalidades de redes sociais analisadas, o Facebook e o Whatsapp são as mais utilizadas. O Facebook lidera, pois todas as empresas pesquisadas fazem uso dele. Dessa forma, é possível constatar que as empresas pesquisadas se aproximam bastante da realidade nacional apresentada na pesquisa de Quintanilha (2012), que encontrou uma média de $80 \%$ das empresas nacionais fazendo uso o Facebook como forma de comunicação.

Quadro 1 - Tipos de redes sociais utilizadas pelas empresas pesquisadas.

\begin{tabular}{|l|l|l|l|l|l|l|}
\hline & Nãousa & Pouquíssimo & Pouco & Maisoumenos & Muito & Muitíssimo \\
\hline Facebook & - & $6,67 \%$ & $6,67 \%$ & $13,33 \%$ & $26,67 \%$ & $46,67 \%$ \\
\hline Twitter & $93,33 \%$ & - & - & $6,67 \%$ & - & - \\
\hline
\end{tabular}




\begin{tabular}{|l|l|l|l|l|l|l|}
\hline You tube & $93,33 \%$ & - & - & $6,67 \%$ & - & - \\
\hline Whatsapp & $13,33 \%$ & - & $6,67 \%$ & $20 \%$ & $26,67 \%$ & $33,33 \%$ \\
\hline Instagram & $40 \%$ & - & - & $13,33 \%$ & $13,33 \%$ & $13,33 \%$ \\
\hline LinkedIn & $100 \%$ & - & - & - & - & - \\
\hline Google+ & $93,33 \%$ & - & - & $6,67 \%$ & - & - \\
\hline Outra (indicar) & - & - & - & - & - & - \\
\hline
\end{tabular}

Fonte: Pesquisa de campo, 2017.

O Quadro 1 mostra ainda que 86,67\% delas utilizam o Whatsapp, enquanto que $60 \%$ usam o Instagram. O Twitter, You Tube, Linkedin e Google+ são redes sociais com pouca freqüência de uso no segmento de confecções investigado.

Segundo pesquisa realizada pela Magoweb (2014), mais de metade dos seus usuários ativos seguem empresas, marcas ou produtos em redes sociais; e $79 \%$ dos usuários estão propensos a recomendar as marcas que eles seguem.

Em conformidade com o Quadro 2, 73,33\% das empresas pesquisadas inserem nas redes sociais fotos dos produtos/serviços na frequência de muito a muitíssimo. Nesta mesma frequência, $60 \%$ delas postam da própria empresa. Verifica-se também que para percentuais abaixo de $20 \%$ na frequência de muito a muitíssimo uso, ações das empresas nas redes sociais são voltadas realizadas por meio de divulgação de fotos dos clientes, vídeos dos produtos/serviços, vídeos da empresa, vídeos dos clientes, depoimentos dos clientes, preços dos produtos e preços dos serviços. Por fim, constatou-se que as empresas divulgam nas redes sociais comentários dos clientes, atendimento pós-venda e especificação de produtos/serviços, respectivamente, com frequência relativa de $40 \%, 33,33 \%$ e $46,66 \%$.

Diante do exposto, constatou-se que as empresas fazem uso das redes sociais com múltiplos propósitos. Segundo Torres (2010), as empresas precisam deixar claro nas redes sociais seus recursos disponíveis, ofertas e produtos oferecidos com o objetivo de atrair os clientes.

Quadro 2 - Recursos utilizados para divulgar a empresa nas redes sociais.

\begin{tabular}{|l|l|l|l|l|l|l|}
\hline & Nãousa & Pouquíssimo & Pouco & $\begin{array}{l}\text { Maisoum } \\
\text { enos }\end{array}$ & Muito & Muitíssimo \\
\hline $\begin{array}{l}\text { Fotos dos } \\
\text { produtos/serviços }\end{array}$ & $6,67 \%$ & $20 \%$ & - & - & $20 \%$ & $53,33 \%$ \\
\hline Fotos da empresa & $20 \%$ & $6,67 \%$ & - & $13,33 \%$ & $20 \%$ & $40 \%$ \\
\hline Fotos dos clients & $60 \%$ & $6,67 \%$ & - & $13,33 \%$ & $6,67 \%$ & $13,33 \%$ \\
\hline $\begin{array}{l}\text { Vídeos dos } \\
\text { produtos/serviços }\end{array}$ & $78,57 \%$ & $7,14 \%$ & $7,14 \%$ & - & $7,14 \%$ & - \\
\hline Vídeos da empresa & $80 \%$ & $6,67 \%$ & $6,67 \%$ & - & $6,67 \%$ & - \\
\hline Vídeos dos clients & $86,67 \%$ & $13,33 \%$ & - & - & - & - \\
\hline $\begin{array}{l}\text { Depoimento dos } \\
\text { clients }\end{array}$ & $40 \%$ & $20 \%$ & $13,33 \%$ & $13,33 \%$ & $6,67 \%$ & $6,67 \%$ \\
\hline
\end{tabular}




\begin{tabular}{|l|l|l|l|l|l|l|}
\hline $\begin{array}{l}\text { Comentários dos } \\
\text { clients }\end{array}$ & $26,67 \%$ & $26,67 \%$ & $6,67 \%$ & - & $40 \%$ & - \\
\hline $\begin{array}{l}\text { Preços dos } \\
\text { produtos }\end{array}$ & $86,67 \%$ & $6,67 \%$ & - & - & $6,67 \%$ & - \\
\hline Preços dos serviços & $73,33 \%$ & $13,33 \%$ & - & - & $13,33 \%$ & - \\
\hline $\begin{array}{l}\text { Atendimentopós- } \\
\text { venda }\end{array}$ & $40 \%$ & $13,33 \%$ & $6,67 \%$ & $6,67 \%$ & $20 \%$ & $13,33 \%$ \\
\hline $\begin{array}{l}\text { Especificação dos } \\
\text { produtos/serviços }\end{array}$ & $26,67 \%$ & $6,67 \%$ & $13,33 \%$ & $6,67 \%$ & $33,33 \%$ & $13,33 \%$ \\
\hline
\end{tabular}

Fonte: Pesquisa de campo, 2017.

Em relação à criação e gestão das redes sociais nas empresas de pesquisadas, $86,67 \%$ fizeram uso dos próprios funcionários para implantar a gestão das redes sociais e monitorar as atividades dessas redes.

O resultado da pesquisa também revelou que 86,67\% das empresas possuem 1 ou 2 pessoas envolvidas diretamente com a gestão das redes sociais, sendo que a maioria trabalha atuam na área de vendas (33,33\%), marketing (20\%) ou são os próprios diretores $(33,33 \%)$. Para Bana (2013), as pessoas que trabalham com gestão das redes sociais devem ser bem treinadas, conhecer o produto que vende e entender que o cliente quer uma resposta rápida. Os profissionais devem estar prontos para atender os diferentes públicos que a organização pode alcançar independente de idade, gênero, escolaridade ou cultura.

A seguir, o quadro 3 exibe as principais razões estratégicas para uso das redes sociais no segmento pesquisado, com base na Escala de Likert (Discordo Totalmente $=\mathrm{DT}$; Discordo Parcialmente=DP; Nem Discordo/Nem Concordo=ND/NC; Concordo Parcialmente=CP; e Concordo Totalmente $=\mathrm{CT}$ ).

As principais estratégias utilizadas pelas empresas pesquisadas estão voltadas para: aumentar a fidelidade do cliente; melhorar a imagem da(s) marca(s); aumentar o volume de vendas; dinamizar as ações de marketing boca a boca; modernizar o modelo de negócio; e melhorar o relacionamento com os clientes, posto que todas as empresas pesquisadas concordaram parcialmente ou totalmente com as razões estratégicas exibidas no Quadro 3.

Para as demais razões exibidas no Quadro 3 as empresas concordaram parcialmente ou totalmente na faixa de percentuais superiores a $70 \%$ e inferiores a $100 \%$. Somente as razões melhorar o relacionamento com os parceiros de negócios e preparar a empresa para a gestão de crises obtiveram percentuais iguais ou inferiores a $60 \%$ de concordância parcial ou total. Esses achados mantêm correlação direta com pesquisa realizada pela Deloitte (2017 apud PEREIRA, 2011), o que permite afirmar que as empresas pesquisas na cidade de Vitória da Conquista estão sintonizadas com as transformações que ocorrem no modo de gerenciamento das empresas, no âmbito da expansão das tecnologias da informação, notadamente das redes sociais. 
Quadro 3 - Razões estratégicas para uso das redes sociais.

\begin{tabular}{|l|l|l|l|l|l|}
\hline \multicolumn{1}{|c|}{ Razões } & \multicolumn{1}{|c|}{ DT } & \multicolumn{1}{c|}{ DP } & ND/NC & \multicolumn{1}{c|}{ CP } & CT \\
\hline Aumentar a fidelidade do cliente & - & - & - & $33,33 \%$ & $66,67 \%$ \\
\hline Melhorar a imagem da(s) marca(s) & - & - & - & $26,67 \%$ & $73,33 \%$ \\
\hline Aumentar o volume de vendas & - & - & - & $13,33 \%$ & $86,67 \%$ \\
\hline Criarvantagem competitive & $6,67 \%$ & $6,67 \%$ & $13,33 \%$ & $20 \%$ & $53,33 \%$ \\
\hline Dinamizar as ações de marketing boca-a-boca & - & - & - & $33,33 \%$ & $66,67 \%$ \\
\hline Modernizar o modelo de negócios & - & - & - & $13,33 \%$ & $86,67 \%$ \\
\hline Melhorar o relacionamento com os clientes & - & - & - & $6,67 \%$ & $93,33 \%$ \\
\hline Melhorar o relacionamento com os parceiros de negócios & $6,67 \%$ & - & $26,67 \%$ & $20 \%$ & $46,67 \%$ \\
\hline Garantir o sucesso de novos produtos & - & $6,67 \%$ & $6,67 \%$ & $26,67 \%$ & $60 \%$ \\
\hline Preparar a empresa para a gestão de crises & $6,67 \%$ & $6,67 \%$ & $26,67 \%$ & $40 \%$ & $20 \%$ \\
\hline Reduzir os custos de aquisição de clientes & $6,67 \%$ & - & $20 \%$ & $33,33 \%$ & $40 \%$ \\
\hline Reduzir os custos de pesquisa de marketing & $6,67 \%$ & - & $20 \%$ & $33,33 \%$ & $40 \%$ \\
\hline Reduzir os custos de atendimento ao cliente & $13,33 \%$ & - & $13,33 \%$ & $26,67 \%$ & $46,67 \%$ \\
\hline Coletar sugestões de ideias inovadoras & - & - & $13,33 \%$ & $40 \%$ & $46,67 \%$ \\
\hline Outros & - & - & - & - & - \\
\hline
\end{tabular}

Fonte: Pesquisa de campo, 2017.

A análise dos dados coletados mostrou que $80 \%$ das organizações pesquisadas possuem de 101 a 10.000 participantes em suas redes sociais, atuando 60\% diariamente, $26,67 \%$ semanalmente e $13,33 \%$ mensalmente. Sendo que $66,67 \%$ desses entram em contato após acesso as redes sociais da empresa, confirmando assim, dados da pesquisa divulgada na Magoweb (2014), na qual se afirma que $79 \%$ das compras na América Latina são influenciadas por recomendações em Redes Sociais.

Outro aspecto importante revelado na pesquisa se refere às principais barreiras para a utilização das redes sociais, na avaliação das empresas.

Quadro 4 - Principais barreiras que impedem a utilização das redes sociais.

\begin{tabular}{|l|l|l|}
\hline & Sim & Não \\
\hline Dificuldade para mensurar os benefícios & $33,33 \%$ & $66,67 \%$ \\
\hline Dificuldade de monitorar a(s) rede(s) social(is) & $33,33 \%$ & $66,67 \%$ \\
\hline Falta de conhecimento no assunto & $40 \%$ & $60 \%$ \\
\hline Falta de adequação à cultura da empresa & $33,33 \%$ & $66,67 \%$ \\
\hline Preocupações com segurança & $60 \%$ & $40 \%$ \\
\hline
\end{tabular}

Fonte:Pesquisa de campo, 2017.

Identificou-se que a preocupação com a segurança é a principal barreira apontada pelas empresas para utilização das redes sociais, representando $60 \%$ do público entrevistado. Uma segunda barreira apontada foi a falta de conhecimento no assunto (40\%), seguida de 
dificuldades para mensurar os benefícios, realizar o monitoramento das informações e promover adequação das redes sociais à cultura da empresa. Silva (2012) acredita que a falta de conhecimento técnico pode ser uma barreira para adoção dessa ferramenta nas empresas brasileiras, pois quando não se tem controle de uma rede social, tornar mais difícil perceber os benefícios dela.

Quadro 5 - Resultados alcançados com o uso das redes sociais.

\begin{tabular}{|l|c|c|}
\hline & Favoráveis & Não favoráveis \\
\hline Aumento do número de clientes & $86,67 \%$ & $13,33 \%$ \\
\hline Aumento das vendas & $86,67 \%$ & $13,33 \%$ \\
\hline Aumento da prestação de serviços & $60 \%$ & $40 \%$ \\
\hline Fidelização de clientes & $60 \%$ & $40 \%$ \\
\hline
\end{tabular}

Fonte: Pesquisa de campo, 2017.

Por fim, merece registrar neste trabalho a avaliação que as empresas fizeram acerca dos resultados alcançados com o uso das redes sociais, conforme mostra o Quadro 5. Pelas questões aplicadas e pelos dados apresentados, foi possível compreender que os gestores e outros envolvidos quantificaram o uso das redes e os recursos usados, sendo um benéfico o uso de redes sociais nas empresas. Constatou-se que todos os percentuais de aprovação das redes sociais se deram em razão do aumento do número de clientes, da maximização das vendas e do número de serviços prestados bem como devido a fidelização dos clientes. $\mathrm{O}$ Quadro 5 mostra que o menor percentual de aprovação foi de $60 \%$ e o maior de $86,67 \%$. Santos (2014) ratifica que com o crescimento das redes sociais e a inovação dos aplicativos, torna-se necessário estar sempre alerta ao impacto gerado pelos públicos virtuais e suas audiências consideráveis para a realização de novos investimentos.

\section{Considerações finais}

Com a construção desse artigo e análise dos resultados encontrados na pesquisa de campo, foi possível identificar que por mais que o uso das redes sociais seja bastante representativo para as empresas no mundo atual, em Vitória da Conquista há espaços para uso mais profissional de redes de comunicação. Trata-se, por conseguinte, de um processo de implantação de uma nova tecnologia que poderá ganhar maturidade organizacional, posto que as evidências coletadas na presente investigação mostraram que os gestores das empresas do segmento de confecção acham que houve benefícios do uso dessa ferramenta tecnológica que 
faz parte da reestruturação de processos de comunicação pessoal e organizacional, porém, como não houve a verificação dos benefícios in loco, então, não pode-se afirmar que eles têm consciência sobre essa questão.

Esse ponto de vista pode estar relacionado com o processo de adaptação das empresas pesquisadas com os novos recursos tecnológicos no âmbito das redes sociais. Constatou-se que as empresas precisam de suporte externo para iniciar a implantação das redes sociais como ferramentas estratégicas para os negócios. Vale ressaltar que as empresas conseguiram destacar os benefícios alcançados, principalmente no que tange ao incremento das vendas e fidelização de clientes.

Entre as redes sociais, o Facebook e Whatsapp são as mais utilizadas no segmento pesquisado. Interessante perceber que na maioria das situações, a gestão de redes sociais se dá pelos próprios funcionários da empresa, ou seja, a reestruturação no ambiente de trabalho tem sido favorável, mesmo que os funcionários enfrentem um processo de adaptação devido à realidade imposta pelos novos recursos tecnológicos no âmbito das redes sociais.

\section{Referências}

ALVES, Giovanni. O novo (e precário) mundo do trabalho. São Paulo: Boitempo, 2000. ANTUNES, Ricardo (org.) Riqueza e miséria no trabalho no Brasil. São Paulo: Boitempo, 1999.

BANA, Fátima A. E-commerce e o pós-vendas. São Paulo, 2013. Disponível em: <http://www.administradores.com.br/artigos/tecnologia/e-commerce-e-o-pos-vendas/69906/>. Acesso em: 17 mar. 2017.

CASTELLS, Manuel. A sociedade em rede. 4. ed. Rio de Janeiro: Paz e Terra, 2000.

CIRIBELI, João P.; PAIVA, Victor H. P. Redes e mídias sociais na internet: realidades e perspectivas de um mundo conectado. Belo Horizonte, Meridional, v. 13, n. 12. 2011.

ECMETRICS - Social Media Solutions. Perfil do brasileiro nas mídias sociais. Estudo Inédito. $1^{\circ}$ semestre, 2011. Disponível em: 〈http://pt.slideshare.net/eCMetricsBrasil/perfildobrasileironasmidiassociais-6906660>. Acesso em: 16 abr. 2017.

FERREIRA, Afonso. Consultor mostra 7 perfis de consumidor nas redes sociais. São Paulo. 2013. Disponível em:

$<$ http://economia.uol.com.br/empreendedorismo/noticias/redacao/2013/12/31/consultormostra-os-7-tipos-de-perfil-de-consumidor-nas-redes-sociais.htm>. Acesso em: 18 jul. 2017.

FONSECA, Virginia Pradelina da Silveira. O jornalismo no conglomerado de mídia: reestruturação produtiva sob o capitalismo global. Tese (Doutorado em Comunicação e Informação). 2005, 350 f. Universidade Federal do Rio Grande do Sul, Porto Alegre - RS, 2005. 
FURLAN, Bruno; MARINHO, Bruno. Redes sociais coorporativas. Instituto Desenvolve T.I. Paraná, 2014. Disponível em: <http://www.desenvolveti.com.br/docs/DesenvolveTIEBookRedesSociaisCorporativas.pdf $>$.Acesso em: 19 abr. 2017.

GUATTARI, Félix. Micropolítica: cartografias do desejo. Petrópolis: Vozes, 1986.

GUIMARÃES, Fabiana Aguiar de O. Redes sociais e suas contradições: espaço de disputa ideo-política. Dissertação (Mestrado em Serviço Social). 2007, 167 f. Faculdade de Serviço Social, Pontifícia Universidade Católica do Rio de Grande do Sul, Porto Alegre, 2007

HAESBAERT, Rogério. O mito da desterritorialização: do “fim dos territórios" à multiterritorialidade. Rio de Janeiro: Bertrand, 2004.

HOBSBAWN, Eric. Mundo do trabalho. 5. ed. São Paulo: Paz e Terra, 2008.

JOHANN, Anthony. Análise da concorrência nas redes sociais. Rio Grande do Sul, 2011. Disponível em: <http://www.administradores.com.br/artigos/marketing/analise-daconcorrencia-nas-redes-sociais/57221/>. Acesso em: 12 abr. 2017.

MAGOWEB Marketing digital. Mídias sociais: conhecendo, aplicando e monitorando. Entenda como você pode trabalhar e monitorar mídias sociais, com foco no Twitter e Facebook. Disponível em: <https://www.dropbox.com/s/wfxk6bbqnmgnp38/midias-sociaisconhecendo-aplicando-e-monitorando.pdf >. Acesso em: 29 mai. 2017.

MARIANO, Luiz Otávio. O papel das redes sociais na estratégia jurídica.Disponível em: $<$ http://www.dcmsestrategia.com.br/redes-sociais-no-estrategia-juridico/> . Acesso em: 04 out. 2017.

OLIVEIRA, F. de. Crítica à razão dualista/O ornitorrinco. São Paulo: Boitempo, 2003.

PEREIRA, Gustavo. Métrica para mídias sociais: um mar de possibilidade parte I. Rio de Janeiro. Dinamize. 2011.

PIZA, Mariana V. O fenômeno Instagram: considerações sob a perspectiva tecnológica. Universidade de Brasília. Instituto de Ciências Sociais. Departamento de Sociologia. Brasília, 2012. Disponível em:

<http://bdm.bce.unb.br/bitstream/10483/3243/1/2012_MarianaVassalloPiza.pdf $>$. Acesso em: 06 jun. 2017.

PORTO, Camila.Facebook marketing: engajamento para transformar fãs em clientes. Paraná. Projeto Gráfico: Ramon Campos. 2014. Disponível em:

$\langle$ http://transformefasemclientes.com.br/ebook/Ebook-Facebook-Marketing.pdf $>$. Acesso em: 01 abr. 2014.

QUINTANILHA, Pedro. Aprenda a trabalhar com mídias sociais em quatro semanas. Rio de Janeiro, 2012. Disponível em: <http://www.pedroquintanilha.com.br/ebook-midiassociais/aprenda-a-trabalhar-com-midias-sociais-em-4-semanas.pdf >. Acesso em: 15 mai. 2017.

RECUERO, Raquel. Redes Sociais na internet. Porto alegre. Meridional Ltda, 2009.

SANTIAGO, André. O uso corporativo da Web 2.0 e seus efeitos no relacionamento com o consumidor. Faculdade de Informática e Administração Paulista. São Paulo, 2009. 
Disponível em: <http://www.bookess.com/read/3110-o-uso-corporativo-da-web-20-e-seusefeitos-no-relacionamento-com-o-consumidor/>. Acesso em: 29 abr. 2017.

SANTOS, Natanael. As redes sociais mais usadas. Natanael Oliveira: seja encontrado e aumente suas vendas. Rio de janeiro, 2014. Disponível:

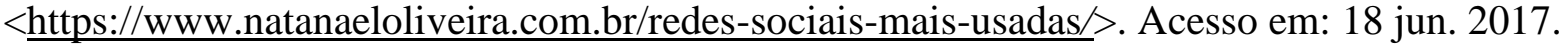

SILVA, Tarcízio. et al. Para entender o monitoramento de mídias sociais.versão 1.0. Bookess. Janeiro, 2012.

SPYER, J.; FERLA L. A.; PAIVA M.; AMORIM F. Twitter: você já aprendeu em uma mesa de bar. Talk2. Rio de Janeiro, 2007. Disponível em:

$<$ http://portaldoprofessor.mec.gov.br/storage/materiais/0000012578.pdf $>$. Acesso em: 02 mai 2014.

THOMPSON, John. A ideologia e cultura moderna: uma teoria social da mídia. 2. ed. Rio de Janeiro, Petrópolis: Vozes, 1999.

TORRES, Cláudio. Guia prático de marketing na internet para pequenas empresas. 2010. Disponível em: 〈http://www.claudiotorres.com.br/mktdigitalpequenaempresa.pdf $>$. Acesso em: 13 mar. 2017.

YIN, Robert K; trad. Daniel Grassi. Estudo de caso: planejamento e métodos. 2. ed. Porto Alegre: Bookman, 2001.

Recebido em: 21/10/2017

Aceito para publicação em: 29/11/2017 